\title{
KENDALA MEMBACA PUISI DAN STRATEGI MODEL COOPERATIVE SCRIPT
}

\author{
Do'atusy Syuroyah, Tazqiah Nuralizza, Tiara Yuliani Sabillah, Maya Dewi Kurnia \\ Universitas Swadaya Gunung Jati (UGJ) Jawa Barat, Indonesia. \\ Email: doatusysyuroyah@gmail.com, alizzatazqiah@gmail.com, tiarays06@gmail.com
}

\begin{abstract}
INFO ARTIKEL ABSTRAK
Diterima

1 Desember 2021

Direvisi

11 Desember 2021

Disetujui

2 Januari 2022

Kata Kunci:

Puisi, Kendala,

Strategi,

Cooperative Script

Kegiatan membaca puisi merupakan salah satu dari kegiatan apresiasi satra yang bertujuan untuk menghargai dan melestarikan sebuah karya sastra. Dalam membaca sebuah puisi dibutuhkan keterampilan berbicara yang harus diperhatikan. Oleh karena itu rumusan masalah ada penelitian ini adalah bagaimana kendala yang dialami siswa ketika membaca puisi? dan bagaimanakah gambaran strategi model cooperative script?. Dengan demikian, tujuan dari penelitian ini adalah mencari tahu kendala yang dialami siswa dan menggambarkan sebuah strategi membaca puisi. Penelitian ini menggunakan metode deskriptif kualitatif. Instrumen yang digunakan dalam penelitian ini berupa kuesioner. Pengambilan data dilakukan dengan teknik wawancara tersusun. Teknik analisis data yang digunakan adalah teknik analisis kualitatif. Penelitian ini mendapatkan hasil bahwa dalam praktek membaca puisi yang berlangsung di sekolah sering kali dijumpai kendala yang dialami oleh siswa. Sistem pembelajaran yang berubah dikala pandemi mengakibatkan perubahan pada pola pembelajaran hal tersebut mengakibatkan perbedaan kendala yang dialami oleh siswa baik sebelum berlangsungnya pandemi atau pada masa pandemi dan dalam penelitian ini juga menggambarkan sebuah strategi membaca puisi berupa metode Cooperative Script yang membutuhkan kerja sama antara dua orang, yang mana yang satu sebagai pembicara dan yang satunya sebagai pendengar.
\end{abstract}
ABSTRACT
The purpose of writing this article is to describe the concept of the story of the Qur'an about character education and the relevance of the stories in the Qur'an to character education. The background of the problem in this research is that the stories in the Qur'an are stories that can be proven archaeologically and scientifically. The stories in the Qur'an in general are makkiyyah verses, which when Islam came, people were in ignorance and jumud behavior. The Qur'an was revealed as a guide for salvation and to provide convenience, to elevate the degree of humanity in accordance with the mission of the Qur'an, the mission of the stories in the Qur'an, and the apostolic mission of the prophet Muhammad SAW. The philosophy, wisdom, and 'ibrah contained are very full of educational messages and values, but must be understood sincerely, logically, systematically and comprehensively. The research method in writing this article is a qualitative approach, tahlili interpretation, with a synthetic analytical method. Conceptually, it starts with reading, taking notes (collecting data), identifying, arranging them in units according to the sequence of thinking patterns, then analyzing to come to a conclusion. So it can be concluded that the stories presented in the Qur'an are the concepts of irsyad (guidance, guidance), hiwar (dialogue), dhikr

$\begin{array}{ll}\text { How to cite: } & \text { Syuroyah, Do'atusy, Tazqiah Nuralizza, Tiara Yuliani Sabillah (2022). Kendala Membaca Puisi Dan } \\ & \text { Strategi Model Cooperative Script, Action Research Literate, 6(1). } \\ \text { E-ISSN: } & 2721-2769 \\ \text { Published by: } & \text { Ridwan Institute }\end{array}$


(reminder), wisdom (philosophical meaning, or lesson), tandzir (warning). The relevance of the stories in the Qur'an to character education, namely stories that are packaged in various forms into alternative methods in the learning process that are easy, interesting and memorable; stories become a medium for conveying messages and

Keywords:

Poetry,

Constraints,

Strategies,

Cooperative Script internalizing values in an effort to develop the morals of students; and stories can be an effective educational method for the development of intelligence and the formation of a strong and obedient soul in accordance with the mission of the story and the apostolic mission of Muhammad SAW.

\section{Pendahuluan}

Kegiatan membaca puisi merupakan salah satu dari kegiatan apresiasi satra yang bertujuan untuk menghargai dan melestarikan sebuah karya sastra (Muslimin, 2017). Dalam membaca sebuah puisi dibutuhkan keterampilan berbicara yang harus diperhatikan. Kelantangan suara menjadi nilai utama dalam keterampilan berbicara yang dibutuhkan ketika membacakan suatu karya sastra. Namun, artikulasi dan intonasi harus diperhatikan dalam kegiatan membaca agar makna yang terkandung dalam puisi dapat tersampaikan dengan jelas dan baik sehingga mampu dipahami oleh para pendengar (ISTIQOMAH, 2019). Kemampuan membaca puisi bukanlah suatu kemampuan yang didapatkan dalam waktu yang singkat melainkan memerlukan proses serta latihan yang panjang untuk mencapai hasil yang maksimal. Dalam proses membaca puisi sering dihadapkan pada berbagai kendala yang dialami siswa baik dari faktor kebahasaan maupun non kebahasaan. Keterampilan membaca menjadi suatu ketarampilan yang penting dalam proses membacakan sebuah karya sastra. Melalui kegiatan praktek membaca puisi dengan baik siswa diharapkan dapat meningkatan keterampilan membaca serta menumbuhkan rasa percaya diri sehingga siswa dapat dengan mudah menampilkan ekspresinya dihadapan umum ketika mengapresiasi sebuah karya sastra (Husna et al., 2020).

Kompetensi Dasar 4.7 Menyimpulkan unsur-unsur pembangun dan makna teks puisi yang diperdengarkan atau dibacaMenjelaskan Pengertian Teks Puisi (Dawud et al., 2020). Kompetensi Indikator 4.7.2 Membacakan puisi (Ekpresi, Lafal, Tekanan, Intonasi).

Oleh karena itu rumusan masalah ada penelitian ini adalah bagaimana kendala yang dialami siswa ketika membaca puisi? dan bagaimanakah gambaran strategi model cooperative script?. Dengan demikian, tujuan dari penelitian ini adalah mencari tahu kendala yang dialami siswa dan menggambarkan sebuah strategi membaca puisi.

Ada beberapa hal yang harus diperhatikan ketika seseorang membacakan sebuah puisi agar pembacaan puisi menjadi enak untuk didengar dan dapat tersampaikan kepada pendengar. Menururt (Nurhadi, 2019) menyatakan bahwa ada tiga unsur utama yang harus diperhatikan sewaktu membaca puisi yaitu (1) pemahaman, berupa sebuah pamahaman mengenai seluk-beluk puisi yang akan dibacakan, (2) penghayatan, berupa menghayati serta menjiwai puisi agar isi puisi tersampaikan kepada para pendengar, (3) pemaparan, berupa memperhatikan kualitas bunyi atau intonasi yang berkaitan dengan kuat-lunak, tinggi-rendahnya bunyi ujaran yang diujarkan. Selain itu, ada Tempo, yaitu pengaturan cepat-lambatnya pengujaran. Pelafalan berkaitan dengan cara mengucapkan bunyi ujaran secara tepat, kuat, dan jelas. Ekspresi berkaitan dengan air muka yang ditampilakn seorang pembaca, serta pembaca juga harus memperhatikan 
pandangan mata, pengaturan posisi tubuh atau dengan pengaturan gerak-gerik tubuh.

Akan tetapi, kenyataannya ketika siswa diminta untuk membacakan sebuah puisi dengan tenik yang baik siswa akan dihadapkan pada beberapa kendala. Kendala yang sering dialami siswa tingkat SLTP berupa faktor kebahasaan yang meliputi intonasi, artikulasi, ekspresi dan kelantangan suara. Hal tersebut disebabkan oleh ketidakbiasaan siswa dalam membaca puisi.

Berdasarkan penelitian yang telah dilakukan oleh (Utami et al., 2018) mengemukakan bahwa kemampuan membaca puisi siswa masih tergolong rendah. Siswa hanya membacakan puisi tanpa memerhatikan intonasi, ekspresi, penghayatan, dan lain-lain. Siswa beranggapan bahwa pembelajaran membaca puisi terlalu sulit. Bahasa yang digunakan oleh penulis sukar untuk dipahami oleh siswa, sehingga saat siswa diminta untuk membacakan puisi di depan kelas, siswa kurang menghayati puisi yang dibaca. Selain itu, kepercayaan diri siswa masih kurang. Siswa masih terlihat malu-malu untuk mengekspresikan puisi yang dibaca, bahkan terkadang siswa menutupi muka dengan teks puisi yang dibaca. Siswa juga tidak memerhatikan intonasi atau tinggi rendah, keras atau lembutnya suara saat membacakan puisi, sehingga irama saat siswa membacakan puisi masih monoton. Selain itu, pelafalan kata-kata dalam puisi masih kurang jelas. Oleh sebab itu, guru dituntut untuk mampu merancang pembelajaran yang merangsang siswa untuk mengembangkan kemampuan membaca puisinya. Guru juga dituntut untuk mampu melaksanakan pembelajaran yang aktif, siswa diharapkan terlibat langsung dalam pembelajaran. Melalui keterlibatan secara langsung, diharapkan siswa memperoleh pengalaman dan pemahaman terhadap membaca puisi (Utami et al., 2018).

Seperti penelitian yang dilakukan oleh (Laguliga et al., 2020) dengan judul "Upaya Peningkatan Keterampilan Membaca Puisi
Pada Siswa Kelas X Sma Negeri 7 Sigi Melalui Metode Cooperative Script" yang dilakukan pada tahun 2017 dengan hasil berupa peningkatan keterampilan membaca puisi yang diperoleh cukup signifikan baik secara individu maupun kelompok. Hal ini dipengaruhi dengan adanya peningkatan dalam keterampilan guru dan aktivitas siswa dalam menerapkan metode cooperative script. Dengan demikian, dapat disimpulkan bahwa metode cooperative script efektif diterapkan dan dapat menjadi alternatif dalam pembelajaran Bahasa Indonesia khususnya pada keterampilan membaca puisi. Hal ini dapat dilihat pada hasil keterampilan membaca puisi siswa pada siklus I, rata-rata nilai yang diperoleh oleh 72 sedangkan pada kondisi awal hanya 61,67 dan pada siklus II rata-rata meningkat menjadi 77,55 dengan KKM 75 (Laguliga et al., 2020).

\section{Metode Penelitian}

Penelitian ini menggunakan metode deskriptif kualitatif (Rahmatunisa,S. \& Febriani, 2019). Penelitian kualitatif adalah jenis penelitian yang dilakukan dengan tidak mengutamakan pada angka-angka, tetapi mengutamakan penghayatan terhadap interaksi antar konsep yang sedang dikaji. Penelitian dilaksanakan dengan tujuan untuk menemukan strategi pembelajaran yang dapat implementasikan dalam kegiatan pembelajaran membaca puisi (Sugiyono, 2017). Sumber data dari penelitian ini adalah guru SMPN 1 Karangsembung, kecamatan Karangsembung, kabupaten Cirebon bernama Triana Retnaningrum, S.Pd.. Instrumen yang digunakan dalam penelitian ini berupa kuesioner. Kuesioner dalam penelitian ini terdiri dari pertanyaan-pertanyaan yang akan dijawab oleh guru menurut KD dan KI. Pengambilan data dilakukan dengan teknik wawancara tersusun. Teknik analisis data yang digunakan adalah teknik analisis kualitatif. 


\section{Hasil dan Pembahasan}

Dalam praktek membaca puisi yang berlangsung di sekolah sering kali dijumpai kendala yang dialami oleh siswa. Sistem pembelajaran yang berubah dikala pandemi mengakibatkan perubahan pada pola pembelajaran hal tersebut mengakibatkan perbedaan kendala yang dialami oleh siswa baik sebelu $\mathrm{m}$ berlangsungnya pandemi atau pada masa pandemi. Kemampuan berbicara dengan baik dan ekspresif memerlukan waktu yang cukup panjang hal ini berkaitan dengan permasalahan yang sering ditemukan dalam penelitian yang telah dilakukan. Artikulasi, intonasi dan ekspresi menjadi sebuah kendala yang banyak dialami oleh siswa dalam membacakan sebuah puisi. Ketika membacakan sebuah puisi di depan kelas, suara yang dikeluarkan oleh siswa cenderung ditahan dan tidak dikeluarkan secara lantang sehingga suara yang keluar mengakibatkan ketidakjelasan pada kata yang diucapkan.

Ketika membacakan puisi banyak siswa yang mengalami kendala dalam membacakan sebuah puisi. Dimasa pandemi seperti saat ini dan ketika sekolah mulai membuka kegiatan Pembelajaran Tatap Muka banyak siswa yang tidak memiliki keberanian untuk tampil didepan kelas guna membacakan sebuah puisi yang disebabkan oleh rasa malu, kurang percaya diri akan kemampuan membaca yang dimiliki serta ketidaknyamanan yang dirasakan siswa ketika harus membaca dengan menggunakan masker. Kemampuan public speaking yang kurang memadai serta kurangnya rasa percaya diri dalam diri siswa mengakibatkan komponen dalam ketarampilan membaca menjadi lemah, artikulasi, intonasi dan ekspresi tidak ditonjolkan dalam membaca suatu puisi. Kelantangan suara menjadi salah satu kendala yang banyak sekali dialami oleh para siswa. Masih banyak siswa yang memilih untuk menahan suara mereka ketika berbicara dihadapan umum padahal sebelumnya siswa telah diberikan motivasi guna menumbuhkan rasa semangat dalam diri siswa.

Dalam mengatasi kendala terdapat beberapa solusi yang dapat diterapkan dalam pembacaan puisi, yaitu siswa diharapkan dapat berlatih public speaking sesering mungkin agar kemampuan berbicara siswa dapat terlatih dengan baik dan siswa harus menyiapkan segala sesuatu yang dibutuhkan dalam pembaca puisi terutama dalam penguasaan suara dan ekspresi.

Untuk memaksimalkan potensi siswa dalam membaca sebuah puisi perlu diberikan suatu strategi yang tepat. Sadiman, dkk (Warsita, 2008: 266) mengemukakan bahwa Strategi pembelajaran adalah usaha-usaha yang terencana dalam memanipulasi sumbersumber belajar agar terjadi proses belajar dalam diri peserta didik. Sedangkan menurut (Nurdin et al., 2015) mengemukakan bahwa strategi pembelajaran diartikan sebagai urutan langkah atau prosedur yang digunakan guru untuk membawa peserta didik dalam suasana tertentu untuk mencapai tujuan belajarnya.

Guru memberikan sebuah strategi pembelajaran berupa menyontohkan melalui video youtube dan lain sebagainnya agar dapat dijadikan sebagai bahan pembelajaran.

Dalam penelitian ini menggambarkan sebuah strategi membaca puisi berupa metode Cooperative Script yang dikemukakan oleh oleh Danserau dan kawan-kawan (1985) dalam (Lathifah, 2019). Cooperative Script adalah metode belajar dimana siswa bekerja berpasangan dan bergantian peran sebagai pembaca atau pendengar dalam mengintisarikan bagian-bagian yang dipelajari. Metode cooperative script merupakan metode belajar yang membutuhkan kerja sama antara dua orang, yang mana yang satu sebagai pembicara dan yang satunya sebagai pendengar. Hal tersebut dapat membantu siswa mencapai indikator yang telah ditentukan (Siregar, 2018). 
Sementara itu, menurut (Vera et al., 2020) Model pembelajaran Cooperative Script adalah kerjasama dalam belajar dan membuat ringkasan atau mengikhtisarkan suatu ide pokok materi yang sedang di pelajari, selain itu siswa belajar menghargai pendapat pasangannya, model ini juga akan melatih aktivitas belajar sehingga setiap siswa mempunyai tugas dalam proses pembelajaran berlangsung (Vera et al., 2020).

\section{Kesimpulan}

Kesimpulan dari penelitian ini dapat disimpulkan bahwa ketika siswa diminta untuk membacakan sebuah puisi dengan tenik yang baik siswa mengalami beberapa kendala. Kendala yang sering dialami siswa tingkat SLPT berupa faktor kebahasaan yang meliputi intonasi, artikulasi, ekspresi dan kelantangan suara. Dengan demikian, stratgei yang menggunakan model cooperative script yang membutuhkan kerja sama antara dua orang, salah satu sebagai pembicara dan satunya sebagai pendengar, dapat menyebabkan siswa mampu memahami intonasi, artikulasi, ekspresi dan kelantangan suara dengan sendirinya yang dibawakan oleh teman lainnya.

\section{BIBLIOGRAFI}

Dawud, M. P., Pratiwi, Y., \& Muzaki, F. I. (2020). Pelajaran BAHASA INDONESIA untuk SMP \& MTs Kelas 7: membangun literasi digital generasi milenial (Jilid 1). Ferril Irham Muzaki.Google Scholar

Husna, T., Setiawan, D. S. A., \& Tryandari, D. R. (2020). Analisis Proses Pembelajaran Membaca Puisi Dengan Strategi Papaaringepeng Pada Mata Kuliah Puisi Mahasiswa Fkip Jurusan Pbs Prodi Pbsi Umn Al Washliyah. Prosiding Seminar Nasional Hasil Penelitian, 3(1), 634-640. Google Scholar

Istiqomah, P. (2019). Peningkatan
Keterampilan Membaca Puisi Dengan Menggunakan Media Audio Visual Di Kelas V Sdn 1 Pasir Gintung Bandar Lampung. UIN Raden Intan Lampung. Google Scholar

Laguliga, S. A., Lembah, G., \& Nur, Y. (2020). Upaya Peningkatan Keterampilan Membaca Puisi Pada Siswa Kelas X Sma Negeri 7 Sigi Melalui Metode Cooperative Script. Bahasantodea, 5(3), 80-86. Google Scholar

Lathifah, I. (2019). Studi Komparasi Antara Penggunaan Metode Cooperative Script Dengan Metode Ceramah Terhadap Interaksi Edukatif Peserta Didik Pada Mata Pelajaran SKI di MA Matholi'ul Falah Langgenharjo Juwana Pati Tahun Pelajaran 2019/2020. IAIN KUDUS. Google Scholar

Muslimin, M. F. (2017). Sastra Dalam Bingkai Komunitas Budaya: Kemanfaatan Budaya Sebagai Unsur Pembangun Karya Sastra. Google Scholar

Nurdin, N., Komatsu, T., AS, M. A., Djalil, A. R., \& Amri, K. (2015). Multisensor and multitemporal data from Landsat images to detect damage to coral reefs, small islands in the Spermonde archipelago, Indonesia. Ocean Science Journal, 50(2), 317-325. Google Scholar

Nurhadi, A. (2019). Kajian Antropologi Sastra Dan Nilai Pendidikan Karakter Dalam Novel Lintang Lantip Karya Aishworo Ang Serta Relevansinya Dengan Pembelajaran Sastra Di Smp. UNS (Sebelas Maret University). Google Scholar

Rahmatunisa,S. \& Febriani, E. (2019). Strategi Public Relations Dalam Membangun Personal Branding Seniman Visual (Studi Deskriptif Kualitatif Strategi Public Relations Dalam Membangun Personal Branding Muklay Sebagai Seniman Visual). 
Komunikologi: Jurnal Ilmiah Ilmu Komunikasi, 16(2), 104-111. Google Scholar

Siregar, N. (2018). Keterampilan Membaca Puisi Menggunakan Cooperative Script. Al-Razi, 18(2), 1-10. Google Scholar

Sugiyono. (2017). Metode Penelitian Kuantitatif, Kualitatif, dan $R \& D$. Alfabeta. Google Scholar

Utami, A. M. S., Purwadi, A. J., \& Arifin, M. (2018). Peningkatan Kemampuan Membaca Puisi Melalui Pemodelan
Pada Siswa Kelas VII A SMP Negeri 16

Kota Bengkulu. Jurnal Ilmiah KORPUS, 2(2), 141-146. Google Scholar

Vera, F., Agustina, R., \& Alimin, A. A. (2020). Pengaruh Model Pembelajaran Cooperative Script Terhadap Keterampilan Berbicara Siswa Kelas VII SMP. EduIndo: Jurnal Pendidikan Bahasa Dan Sastra Indonesia, 1(1). Google Scholar

\section{Copyright holder :}

Do'atusy Syuroyah, Tazqiah Nuralizza, Tiara Yuliani Sabillah (2022).

First publication right :

Action Research Literate

This article is licensed under: 